\title{
Phylogenetic positions of some genera and species of the family Buccinidae (Gastropoda: Mollusca) from China based on ribosomal RNA and COI sequences
}

\author{
HOU Lin ${ }^{1 *}$, DAHMS Hans-Uwe ${ }^{2}$, DONG Chang Yong ${ }^{1}, \mathrm{CHEN} \mathrm{YiFei}^{1}$, HOU HaoChen $^{1}$, \\ YANG WanXi ${ }^{3} \&$ ZOU XiangYang ${ }^{4}$ \\ ${ }^{1}$ College of Life Science, Liaoning Normal University, Dalian 116081, China; \\ ${ }^{2}$ Sangmyung University, Green Life Science Department, 7 Hongji-dong, Jongno-gu, Seoul 110-743, Korea; \\ ${ }^{3}$ College of Life Sciences, Zhejiang University, Hangzhou 310058, China; \\ ${ }^{4}$ Department of Biotechnology, Dalian Medical University, Dalian 116044, China
}

Received January 21, 2013; accepted March 27, 2013

\begin{abstract}
A phylogenetic analysis of members of the family Buccinidae was conducted using 18S rRNA gene, 28S rRNA gene and the mitochondrial cytochrome oxidase I gene. We studied 18 species of Buccinidae that belong to eight different genera and inhabit the China coastal seas. We analyzed the patterns of divergence between an outgroup and basal ingroup taxa, the monophyly of the genus Neptunea, and the position of one unnamed species within the Buccinidae. A phylogenetic tree (neighbor-joining (NJ) method) was reconstructed based on the sequences of $18 \mathrm{~S}$ rRNA, 28S rRNA and COI, with Rapana venosa as outgroup. The NJ tree indicated that the 18 species could be divided into five groups. The genus Buccinum was monophyletic, whereas Neptunea was shown to be paraphyletic since it included Siphonalia subdilatata and Neptunea sp., a new species. This novel species otherwise clustered consistently with Neptunea cumingi in three other phylogenetic trees, showing a low genetic distance and divergence percentage of sequences belonging to the genus Neptunea. A smaller genetic distance and a smaller difference of 18S rRNA, 28S rRNA and COI sequences between Neptunea cumingii and Neptunea arthritica cumingii confirmed them to be the same species.
\end{abstract}

Buccinidae, molecular phylogenetics, 18S rRNA gene, 28S rRNA gene, COI

Citation: Hou L, Dahms H U, Dong C Y, et al. Phylogenetic positions of some genera and species of the family Buccinidae (Gastropoda: Mollusca) from China based on ribosomal RNA and COI sequences. Chin Sci Bull, 2013, 58: 2315-2322, doi: 10.1007/s11434-013-5922-z

The whelk family Buccinidae contains hundreds of species, which inhabit the oceans of the world. Buccinidae whelks are carnivorous, some being predators of other mollusks and some being scavengers. These large whelks have great commercial value as seafood and the shells are used for ornamental purposes. For the management of these species, knowledge of intraspecific genetic variations are necessary to assess extinction risks, such as inbreeding, and their evolutionary potential in a changing world [1]. At present, the taxonomic status and the phylogenetic relationships of these species are still in dispute. In previous studies, Golikov de-

*Corresponding author (email: houlin@1nnu.edu.cn) scribed 86 species and six subspecies from oceans worldwide [2], whereas Tiba and Kosuge described 107 species and nine subspecies from the North Pacific [3], and Higo et al. [4] described 68 species and 13 subspecies from the vicinity of Japan. It has been reported that 31 species of the family Buccinidae are distributed along the coast of China, but some species are threatened by extinction due to environmental deterioration in recent years [5-7]. Cai et al. [8] suggested that the families Buccinidae, Galeodiadae, Nassidae, Fasciolariidae and Columbellidae belong to the superfamily Buccinacea, but this term has not been used in recent years. Buccinum perryi was allocated to the genus Buccinum, but in subsequent studies, Buccinum perryi had been 
attributed to the genus Volutharpa and was renamed as Volutharpa ampullaceal perryi $[7,8]$. Some taxonomic studies on this family have been reported from the China coast.

The taxonomy of different species and families depends mostly on a high level of homoplasy observed in several morphological characters that are caused by similar lifestyles [9]. Phylogenetic relationships among buccinid species were initially established for several morphoanatomical characters, mainly with respect to characters of the shell [10]. However, more and more molecular markers are used to infer phylogenetic relationships among the Gastropoda (Mollusca) based on DNA and RNA sequences $[11,12]$. Phylogenetic relationships with a high potential in the absence of sufficient morphological characters can be resolved by molecular phylogenetic techniques according to coded characters [13]. A small-subunit ribosomal gene (18S rRNA) was shown to be an effective tool to estimate phylogenetic relationships in gastropods [14]. Thus, molecular distinctions of two otherwise identical abalone species were made using $18 \mathrm{~S}$ rDNA sequences, while the phylogeny of the six vetigastropod subgroups and Littorinidae were studied based on 18S rRNA sequences [15-17]. Using the mitochondrial 16S rRNA gene, the phylogenies of eight species of the genus Buccinum and of 35 species of the family Buccinidae were analyzed by Iguchi et al. [18] and by Hayashi [19], respectively. 28S rRNA was also used to evaluate the major adaptive radiation of some buccinid life forms [20]. However, there is currently no report on molecular phylogenies of whelk species from the coast of China.

In the present study, the phylogeny of 18 species of the family Buccinidae was investigated using 18S rRNA, 28S rRNA and mitochondrial cytochrome oxidase I (COI) gene sequences. The aim was to assess: (1) the phylogenetic relationships of 18 species of the family Buccinidae; (2) the taxonomic status of 18 Chinese species of the family Buccinidae based on DNA sequences.

\section{Materials and methods}

\subsection{Samples}

The 15 species of the family Buccinidae used in this study were collected from the coast of China (Figure 1). The $18 \mathrm{~S}$ rRNA, 28S rRNA and COI sequence data of 3 other species were obtained from GenBank (http://www.ncbi.nlm.nih.gov/). The distribution, collection locations, GenBank accession numbers and abbreviations of the names of the 18 species and Rapana venosa as out group are shown in Table 1.

\subsection{DNA isolation}

Total genomic DNA of five individuals from each species was extracted from muscle tissue. The tissue was minced and lysed in $500 \mu \mathrm{L}$ TE buffer $\left(10 \mathrm{mmol} \mathrm{L}{ }^{-1}\right.$ Tris- $\mathrm{HCl}$, $1 \mathrm{mmol} \mathrm{L}^{-1}$ EDTA), after which $25 \mu \mathrm{L} 10 \%$ SDS and $5 \mu \mathrm{L}$

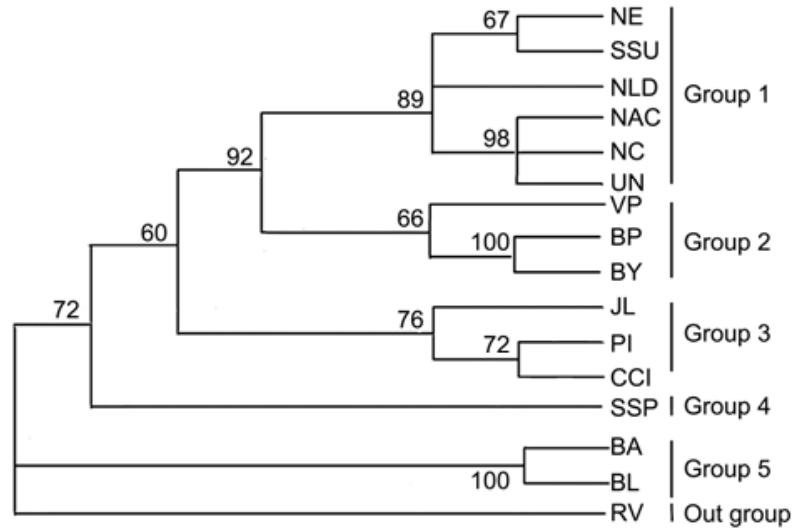

Figure 1 Neighbor-joining (NJ) tree constructed from alignments of $18 \mathrm{~S}$ rRNA sequences using the Kimura 2-parameter model for 15 Buccinidae species from China. Bootstrap values are shown above branches supported in at least 50\% of 1000 replicates. Outgroup: RV, the Asian whelk Rapana venosa.

$20 \mathrm{mg} \mathrm{mL}^{-1}$ of proteinase $\mathrm{K}$ were added, respectively. After incubation for $3 \mathrm{~h}$ at $55^{\circ} \mathrm{C}$, the suspension was extracted with a standard phenol-chloroform extraction protocol according to Sun et al. [21] and Hou et al. [22]. The genomic DNA was precipitated from the lysate with $100 \%$ ethanol, then washed twice with $75 \%$ ethanol and solubilized in $100 \mu \mathrm{L}$ of bidistilled water. DNA quality and quantity were determined by $0.8 \%$ agarose gel electrophoresis.

\subsection{PCR amplification}

Nearly complete sequences of the 18S rRNA and 28S rRNA genes and a partial sequence of mitochondrial DNA COI were amplified by polymerase chain reaction (PCR). The primer sequences are shown in Table 2. Each PCR had a reaction volume of $20 \mu \mathrm{L}$ and contained $2.5 \mu \mathrm{L}$ of $10 \times \mathrm{LA}$ PCR buffer (TaKaRa, Japan), $2.5 \mu \mathrm{L}$ of $0.2 \mathrm{mmol} \mathrm{L}^{-1}$ of dNTP, $0.4 \mu \mathrm{L}$ of each primer, $0.1 \mu \mathrm{L}$ of $0.5 \mathrm{U}$ LA Taq polymerase (TaKaRa), and $0.8 \mu \mathrm{L}$ genomic DNA. PCR was performed using a TC-412 PCR system. The temperature regime used for the amplification of 18S rRNA sequences comprised an initial denaturation step at $94^{\circ} \mathrm{C}$ for $5 \mathrm{~min}$, followed by 35 circles consisting of a denaturation step at $94^{\circ} \mathrm{C}$ for $1 \mathrm{~min}$, annealing at $60.5^{\circ} \mathrm{C}$ for $45 \mathrm{~s}$, and extension at $72^{\circ} \mathrm{C}$ for $2 \mathrm{~min}$. An additional extension step at $72^{\circ} \mathrm{C}$ for 10 min was added. The initial denaturation and final extension step of the PCR procedures of $28 \mathrm{~S}$ rRNA and COI were similar to $18 \mathrm{~S}$ rRNA. Thirty-five cycles were used for $28 \mathrm{~S}$, which included denaturation at $94^{\circ} \mathrm{C}$ for $35 \mathrm{~s}$, annealing at $50^{\circ} \mathrm{C}$ for $30 \mathrm{~s}$, and extension at $72^{\circ} \mathrm{C}$ for $90 \mathrm{~s}$. In addition, 30 cycles were used for $\mathrm{COI}$, which included denaturation at $94^{\circ} \mathrm{C}$ for $30 \mathrm{~s}$, annealing at $40^{\circ} \mathrm{C}$ for $30 \mathrm{~s}$, and extension at $72^{\circ} \mathrm{C}$ for $1 \mathrm{~min}$. The remaining products were purified by a DNA Fragment Purification Kit Version 2.0 (TaKaRa).

\subsection{Sequencing}

The purified products were cloned using PMD18-T vectors, 
Table 1 Distribution, collection locations, and GenBank accession numbers of 18 Buccinidae species used in this study

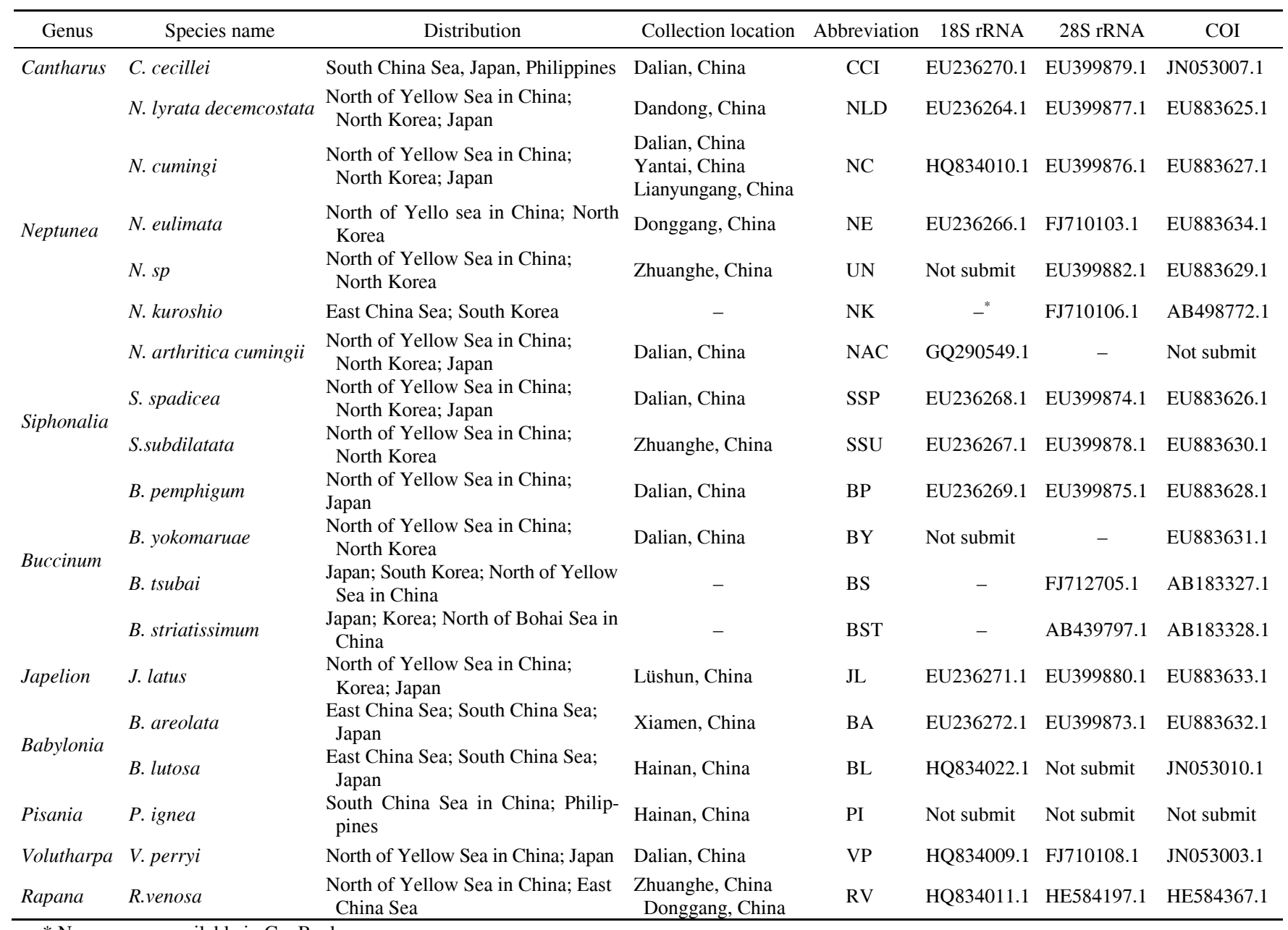

* No sequence available in GenBank.

Table 2 Primers used in this study

\begin{tabular}{cl}
\hline Gene & Sequences \\
\hline \multirow{2}{*}{ 18S rRNA } & 5'-CCTggTTgATCCTgCCAg-3' \\
& 5'-TAATgATCCTTCCgCAggTTA-3' \\
28S rRNA & 5'-gACCCgTCTTgAAACACggA-3' \\
& 5'-AgCCAATCCTTATCCCgAAg-3' \\
COI & 5'-ggTCAACAAATCATAAAgATATTgg-3' \\
& 5'-TAAACTTCAgggTgACCAAAAAATCA-3' \\
\hline
\end{tabular}

thus transforming DH5 $\alpha-$ E.coli cells. The plasmid was isolated from recombinant cells using the alkaline lysis method [23]. It was sequenced directly using the dye-terminator cycle sequencing reaction (PerkinElmer CO. USA) with an ABI PRISM $^{\mathrm{TM}}$ 377XL DNA sequencer and ABI PRISM ${ }^{\mathrm{TM}}$ 3730XL DNA analyzer. Sequencing reactions were performed with BigDye ${ }^{\circledR}$ Terminator v3.1 Cycle Sequencing Kit (Applied Biosystems) using the primers of two universal M13-47 and RV-M primers supplied with the kit (TaKaRa). The fragments were sequenced from both strands to obtain accurate sequences. All final sequences were obtained from both strands for verification. All sequences were submitted to GenBank (http: //www.ncbi.nlm.nih.gov).

\subsection{Phylogenetic analyses}

Sequences were aligned using ClustalX [24] and the extent of sequence difference between individuals was calculated by averaging pairwise comparisons of sequence differences across all individuals. For congruence evaluation the parti- 
tion homogeneity test of the software program PAUP $4.0 \mathrm{~b}$ [25] was used. Phylogenetic trees were constructed using the Neighbor-Joining tree provided by the software program MEGA 4.1 [26], based on the Kimura 2-parameter method [27]. The data was set to 1000 bootstraps in the test of inferred phylogenies to estimate the internal stability of the tree nodes.

\section{Results}

\subsection{Characterization of 18S, $28 \mathrm{~S}$ rRNA and COI gene sequences of 18 whelk species}

The length of 18 species of $18 \mathrm{~S}$ rRNA sequence ranged from 1828 bp in Neptunea arthritica cumingii to 2031 bp in Buccinum pemphigum, while the $28 \mathrm{~S}$ rRNA sequence ranged from 686 bp in Buccinum subai to 1640 bp in Japelion latus, and the COI sequences ranged from 490 bp in Buccinum tsubai and Buccinum striatissimum to 698 bp in Neptunea sp.

The genetic distance and the ratio of transitions/transversions and genetic distance of these 18 whelk species based on the 18S rRNA, 28S rRNA and COI gene sequences are listed in Tables 3-5, respectively. The experimental results showed that the longest distance between SSP and $\mathrm{JL}$ was 0.022 based on 18S rRNA, and the longest distance value between BST and CCI based on 28S rRNA was 0.372. In addition, the shortest distance based on 18S rRNA was 0.002 between BL and BA, NC and NAC, respectively. The shortest distance based on 28S rRNA was 0.003 between NLD and NK. Based on the COI sequences, the longest genetic distance was 0.465 between BA and BST and the shortest genetic distance was 0.000 between UN and NC, $\mathrm{NC}$ and NAC, UN and NAC and BA and BY, respectively (Table 5).

Table 3 Ratio of transitions/transversions (above diagonal) and genetic distances (below diagonal) under Kimura's 2-parameter model of 15 species of the family Buccinidae inferred from $18 \mathrm{~S}$ rRNA sequences

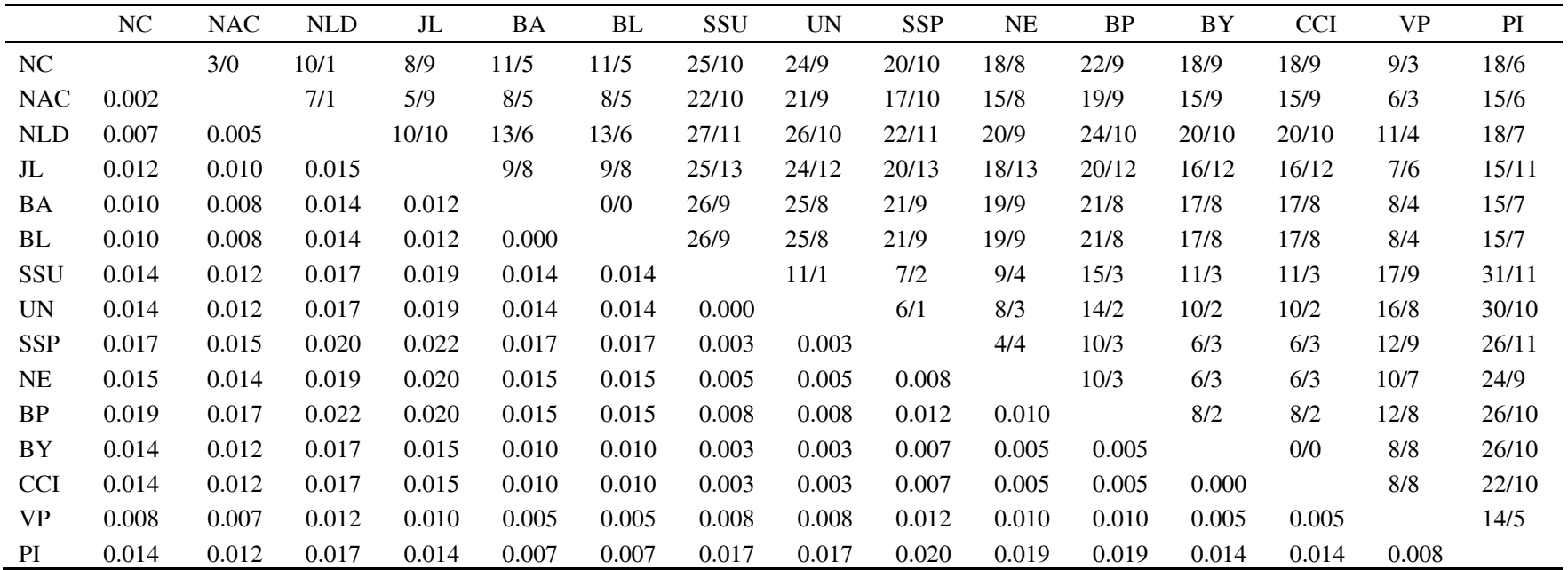

Table 4 Ratio of transitions/transversions (above the diagonal) and genetic distances (below the diagonal) of 28S rRNA sequences from 15 Buccinidae species

\begin{tabular}{|c|c|c|c|c|c|c|c|c|c|c|c|c|c|c|c|}
\hline & VP & BS & NK & UN & NLD & $\mathrm{NE}$ & SSU & $\mathrm{JL}$ & BA & SSP & BP & BL & $\mathrm{NC}$ & BST & $\mathrm{CCI}$ \\
\hline VP & & $6 / 3$ & $13 / 8$ & $17 / 22$ & $17 / 22$ & $17 / 22$ & $16 / 21$ & $17 / 22$ & $17 / 22$ & $17 / 22$ & $17 / 21$ & $17 / 22$ & $16 / 22$ & $15 / 21$ & $16 / 23$ \\
\hline BS & 0.115 & & $13 / 8$ & $16 / 22$ & $17 / 21$ & $16 / 22$ & $16 / 21$ & $17 / 22$ & $17 / 22$ & $17 / 21$ & $17 / 21$ & $17 / 21$ & $16 / 21$ & $16 / 20$ & $16 / 23$ \\
\hline NK & 0.259 & 0.253 & & $17 / 22$ & $17 / 21$ & $17 / 22$ & $17 / 21$ & $17 / 22$ & $17 / 22$ & $17 / 21$ & $18 / 21$ & $18 / 21$ & $17 / 21$ & $16 / 21$ & $16 / 22$ \\
\hline UN & 0.215 & 0.235 & 0.010 & & $3 / 1$ & $3 / 2$ & $5 / 2$ & $7 / 14$ & $12 / 8$ & $6 / 12$ & $11 / 8$ & $12 / 10$ & $12 / 7$ & $16 / 26$ & $16 / 26$ \\
\hline NLD & 0.012 & 0.327 & 0.003 & 0.015 & & $4 / 1$ & $6 / 1$ & $8 / 15$ & $13 / 7$ & $7 / 11$ & $9 / 9$ & $10 / 11$ & $13 / 6$ & $16 / 26$ & $16 / 25$ \\
\hline SSU & 0.015 & 0.220 & 0.018 & 0.119 & 0.015 & 0.009 & & $7 / 11$ & $14 / 4$ & $7 / 9$ & $12 / 7$ & $13 / 9$ & $15 / 7$ & $16 / 26$ & $16 / 25$ \\
\hline $\mathrm{JL}$ & 0.217 & 0.256 & 0.215 & 0.211 & 0.126 & 0.210 & 0.210 & & $11 / 16$ & $9 / 15$ & $13 / 12$ & $13 / 14$ & $17 / 16$ & $17 / 27$ & $16 / 26$ \\
\hline BA & 0.219 & 0.239 & 0.281 & 0.215 & 0.221 & 0.215 & 0.215 & 0.226 & & $6 / 9$ & $10 / 7$ & $11 / 9$ & $19 / 9$ & $17 / 26$ & $16 / 26$ \\
\hline SSP & 0.231 & 0.271 & 0.310 & 0.210 & 0.215 & 0.210 & 0.210 & 0.221 & 0.265 & & $8 / 6$ & $9 / 8$ & $15 / 13$ & $17 / 26$ & $16 / 26$ \\
\hline BP & 0.187 & 0.023 & 0.221 & 0.136 & 0.231 & 0.186 & 0.136 & 0.247 & 0.231 & 0.326 & & $2 / 0$ & $20 / 13$ & $17 / 26$ & $16 / 26$ \\
\hline BL & 0.192 & 0.265 & 0.275 & 0.231 & 0.226 & 0.231 & 0.231 & 0.242 & 0.026 & 0.221 & 0.205 & & $21 / 15$ & $17 / 26$ & $16 / 26$ \\
\hline BST & 0.292 & 0.009 & 0.167 & 0.255 & 0.269 & 0.217 & 0.297 & 0.279 & 0.233 & 0.255 & 0.291 & 0.291 & 0.287 & & $16 / 23$ \\
\hline $\mathrm{CCI}$ & 0.321 & 0.275 & 0.316 & 0.311 & 0.305 & 0.326 & 0.326 & 0.013 & 0.287 & 0.305 & 0.366 & 0.366 & 0.323 & 0.372 & \\
\hline
\end{tabular}


Table 5 The ratio of transitions/transversions (above the diagonal) and genetic distances (below the diagonal) of COI sequences from 18 Buccinidae species

\begin{tabular}{|c|c|c|c|c|c|c|c|c|c|c|c|c|c|c|c|c|c|c|}
\hline & $\mathrm{NC}$ & $\mathrm{N}$ & NAC & NE & SSU & NLD & NK & BP & BY & BS & BST & VP & PI & $\mathrm{CCI}$ & $\mathrm{JL}$ & SSP & BA & BL \\
\hline $\mathrm{NC}$ & & $0 / 0$ & $0 / 0$ & $25 / 2$ & $31 / 2$ & $36 / 2$ & $36 / 4$ & $30 / 27$ & $39 / 22$ & $42 / 21$ & $/ 31$ & & $2 / 31$ & $5 / 30$ & $9 / 22$ & $2 / 24$ & $4 / 40$ & $6 / 48$ \\
\hline UN & 0.000 & & $0 / 0$ & $25 / 2$ & $31 / 2$ & $36 / 2$ & $36 / 4$ & $39 / 22$ & $39 / 22$ & $42 / 21$ & $32 / 31$ & $40 / 22$ & $/ 31$ & $45 / 30$ & 39 & 24 & $44 / 40$ & $46 / 48$ \\
\hline NAC & 0.000 & 0.000 & & $25 / 2$ & $31 / 2$ & $36 / 2$ & $36 / 4$ & $39 / 22$ & $39 / 22$ & $42 / 21$ & $32 / 31$ & $40 / 22$ & $32 / 31$ & $45 / 30$ & $39 / 22$ & $42 / 24$ & $42 / 42$ & $46 / 48$ \\
\hline $\mathrm{NE}$ & 0.114 & 0.114 & 0.114 & & $21 / 2$ & $30 / 2$ & $29 / 4$ & $38 / 22$ & $38 / 22$ & $39 / 21$ & $36 / 31$ & $37 / 22$ & $36 / 31$ & $46 / 30$ & $35 / 22$ & $40 / 24$ & $48 / 40$ & $44 / 50$ \\
\hline SSU & 0.131 & 0.131 & 0.131 & 0.091 & & $36 / 2$ & $33 / 2$ & $47 / 20$ & $47 / 20$ & $44 / 19$ & $1 / 31$ & $44 / 20$ & $41 / 31$ & $52 / 30$ & $39 / 22$ & 24 & 38 & $50 / 48$ \\
\hline NK & 0.155 & 0.155 & 0.155 & 0.138 & 0.156 & 0.155 & & $49 / 20$ & $49 / 20$ & $50 / 19$ & $41 / 29$ & $43 / 20$ & $41 / 29$ & $49 / 30$ & $39 / 20$ & $49 / 22$ & $47 / 38$ & $48 / 46$ \\
\hline BP & 0 & 0 & 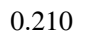 & 0 & 9 & 0.219 & 0.239 & & $0 /$ & $35 / 5$ & 15 & 10 & 5 & 6 & 4 & 0 & 8 & $50 / 44$ \\
\hline BY & 0.210 & 0.210 & 0.210 & 0.210 & 0.269 & 0.219 & 0.239 & 0.000 & & $35 / 5$ & $35 / 5$ & $38 / 10$ & $45 / 35$ & $53 / 36$ & $43 / 20$ & $46 / 30$ & $47 / 38$ & $50 / 44$ \\
\hline BS & 0.257 & 0.257 & 0.257 & 0.257 & 0.279 & 0.228 & 0.312 & 0.165 & 0.165 & & $30 / 4$ & $35 / 9$ & $39 / 34$ & $45 / 33$ & $43 / 19$ & $45 / 25$ & $56 / 39$ & $58 / 45$ \\
\hline BST & 0.239 & 0.239 & 0.239 & & 0.337 & 0.323 & 0.303 & 0.222 & 0.222 & 0.166 & & & $45 / 34$ & $53 / 35$ & & $51 / 25$ & $52 / 39$ & $57 / 45$ \\
\hline VP & 0.238 & 0.238 & 0.238 & 0.247 & 0.290 & 0.210 & 0.239 & 0.180 & 0.180 & 0.208 & 0.271 & & $43 / 33$ & $44 / 34$ & $38 / 20$ & $44 / 24$ & $46 / 37$ & $47 / 45$ \\
\hline $\mathrm{CCI}$ & 0.334 & 0.334 & 0.334 & 0.334 & 0.408 & 0.323 & 0.370 & 0.343 & 0.343 & 0.324 & 0.393 & 0.316 & 0.213 & & $37 / 26$ & $47 / 26$ & $50 / 47$ & $54 / 55$ \\
\hline JL & 0.235 & 0.235 & 0.235 & 0.226 & 0.255 & 0.284 & 0.210 & 0.257 & 0.257 & 0.267 & 0.312 & 0.230 & 0.160 & 0.247 & & $35 / 26$ & $48 / 40$ & $51 / 48$ \\
\hline SSP & 0.253 & 0.253 & 0.253 & 0.253 & 0.304 & 0.262 & 0.307 & 0.244 & 0.244 & 0.245 & 0.305 & 0.275 & 0.227 & 0.340 & 0.216 & & $42 / 36$ & $43 / 44$ \\
\hline BA & 0.361 & 0.361 & 0.361 & 0.405 & 0.394 & 0.420 & 0.351 & 0.410 & 0.410 & 0.491 & 0.465 & 0.377 & 0.389 & 0.481 & 0.363 & 0.341 & & $4 / 8$ \\
\hline BL & 0.391 & 0.391 & 0.391 & 0.437 & 0.425 & 0.452 & 0.380 & 0.419 & 0.419 & 0.515 & 0.488 & 0.394 & 0.431 & 0.529 & 0.393 & 0.359 & 0.026 & \\
\hline
\end{tabular}

\subsection{Analysis of phylogeny based on the $18 \mathrm{~S}$ rRA, $28 \mathrm{~S}$ rRNA and COI genes sequences}

A neighbor-joining (NJ) tree was constructed using genetic distances by means of the Kimura 2-parameter [27]. Phylogenetic trees of the 15 species were constructed by using 18S rRNA (Figure 1) and 28S rRNA sequences (Figure 2), whereas a phylogenetic tree of 18 species was inferred from COI gene sequences (Figure 3), respectively.

In the $18 \mathrm{~S}$ rRNA, $28 \mathrm{~S}$ rRNA and COI sequences, transitions and transversions were the main form of transformations of bases. The average ratios of transitions to transversions were $2.52,1.01$ and 2.56 , respectively. The nucleotide compositions were T: $25.2 \%, \mathrm{C}: 22.9 \%$, A: $24.3 \%$, G:

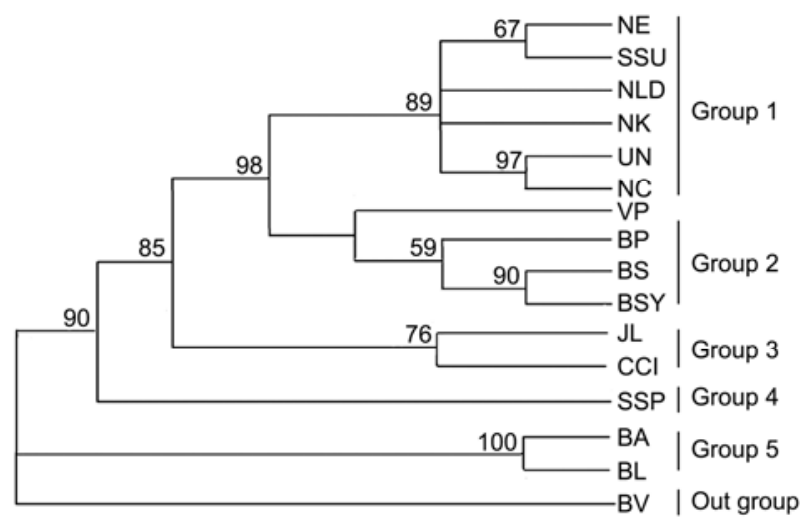

Figure 2 Neighbor-joining (NJ) tree constructed from alignments of $28 \mathrm{~S}$ rRNA sequences using the Kimura 2-parameter model for 15 Buccinidae species from China. Bootstrap values are shown above branches supported in at least $50 \%$ of 1000 replicates. Outgroup: RV, the Asian whelk Rapana venosa.

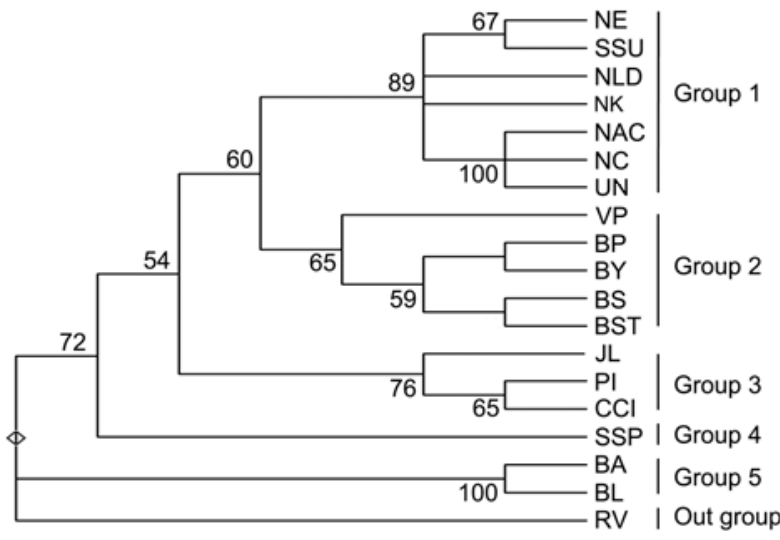

Figure 3 Neighbor-joining (NJ) tree constructed from alignments of COI sequences using the Kimura 2-parameter model for 18 Buccinidae species from China. Bootstrap values are shown above branches supported in at least $50 \%$ of 1000 replicates. Outgroup: RV, the Asian whelk Rapana venosa.

$27.6 \%$ in the $18 \mathrm{~S}$ rRNA sequence, $\mathrm{T}: 23.9 \%, \mathrm{C}: 31.4 \%, \mathrm{~A}$ : $20.2 \%$, G: $24.5 \%$ in the $28 \mathrm{~S}$ rRNA sequence, and T: $37.3 \%$, C: $17.6 \%$, A: $25.9 \%$, G: $19.2 \%$ in the COI sequence.

The three resulting phylogenetic trees were very similar. In the NJ tree resulting from all three gene sequences the individuals were divided into five groups: Neptunea eulimata (NE), Siphonalia subdilatata (SSU), Neptunea lyrata decemcostata (NLD), Neptunea cumingi (NC). Neptunea arthritica cumingii (NAC) and an unnamed species (UN) clustered as group 1; Volutharpa perryi (VP) Buccinum pemphigum (BP), Buccinum yokomaruae (BY), Buccinum tsubai (BS) and Buccinum striatissimum (BST) were grouped in group 2; group 3 accommodated Japelion latus (JL) Pisania ignea (PI) and Cantharus cecillei (CCI); group 
4 included only Siphonalia spadicea (SSP); group 5 contained Babylonia areolata (BA) and Babylonia lutosa (BL). The unnamed species formed a sister clade with NC in all three phylogenetic trees. BY and BP of the genus Buccinum were consistently in the same group. However, SSU did not cluster with SSP, although they belonged to the same genus.

To detect the differences within species, the phylogenetic tree of the 50 individuals of 10 most common buccinid species was inferred from $28 \mathrm{~S}$ rRNA gene sequences. A neighbor-joining (NJ) tree was constructed using genetic distances by means of the Kimura 2-parameter [27] (Figure 4).

\section{Discussion}

18S rRNA is very conservative gene and has therefore been suggested by some researchers as a phylogenetic marker to trace the relationships among distantly related taxa $[15,16$, 28-30]. The 28S rRNA gene has a low transitional ratio and is more conservative in evolutionary transitions. This makes them more suitable for the study of phylogenetic relationships of taxa higher than the genus level [31]. However, the $18 \mathrm{~S}$ rRNA sequence has also been shown to be useful in the phylogenetic analyses of congeneric species [32-37]. By using single sequences for the evaluation of phylogenies, resulting information seems limited, and the results are arbitrary. In order to avoid conflicting phylogenies among $18 \mathrm{~S}$ rRNA, 28S rRNA and COI gene sequences, combined sequences are generally used for phylogenetic reconstructions [38]. In an earlier study, phylogenetic relationships among 21 species of stromateoid fishes, representing five families and 13 genera, were reconstructed using 3263 bp of mitochondrial DNA sequences, including the posterior half of the 16S rRNA and the entire COI and Cytb genes [39]. The experimental results of the present study showed no conflicts among the 18S rRNA, 28S rRNA, and COI gene sequences. This provides evidence for the reliability and usefulness of combining the $18 \mathrm{~S}$ rRNA, 28S rRNA, and COI gene sequences as molecular markers in the present study. However, since $18 \mathrm{~S}$ rRNA or $28 \mathrm{~S}$ rRNA sequences were not available for some species, an analysis of the phylogeny of all 18 species of the family Buccinidae could not be carried out using the combined sequence information.

Knight and Mindell suggested that a mutant gene sequence reaches saturation if the ratio of transitions/ transversions ( $\mathrm{Ts} / \mathrm{Tv})$ was less than 2.0 [40]. In the present study, the Ts/Tv value of the $18 \mathrm{~S}$ rRNA gene sequence was 1.015 as determined by MEGA 4.0, which means that it was

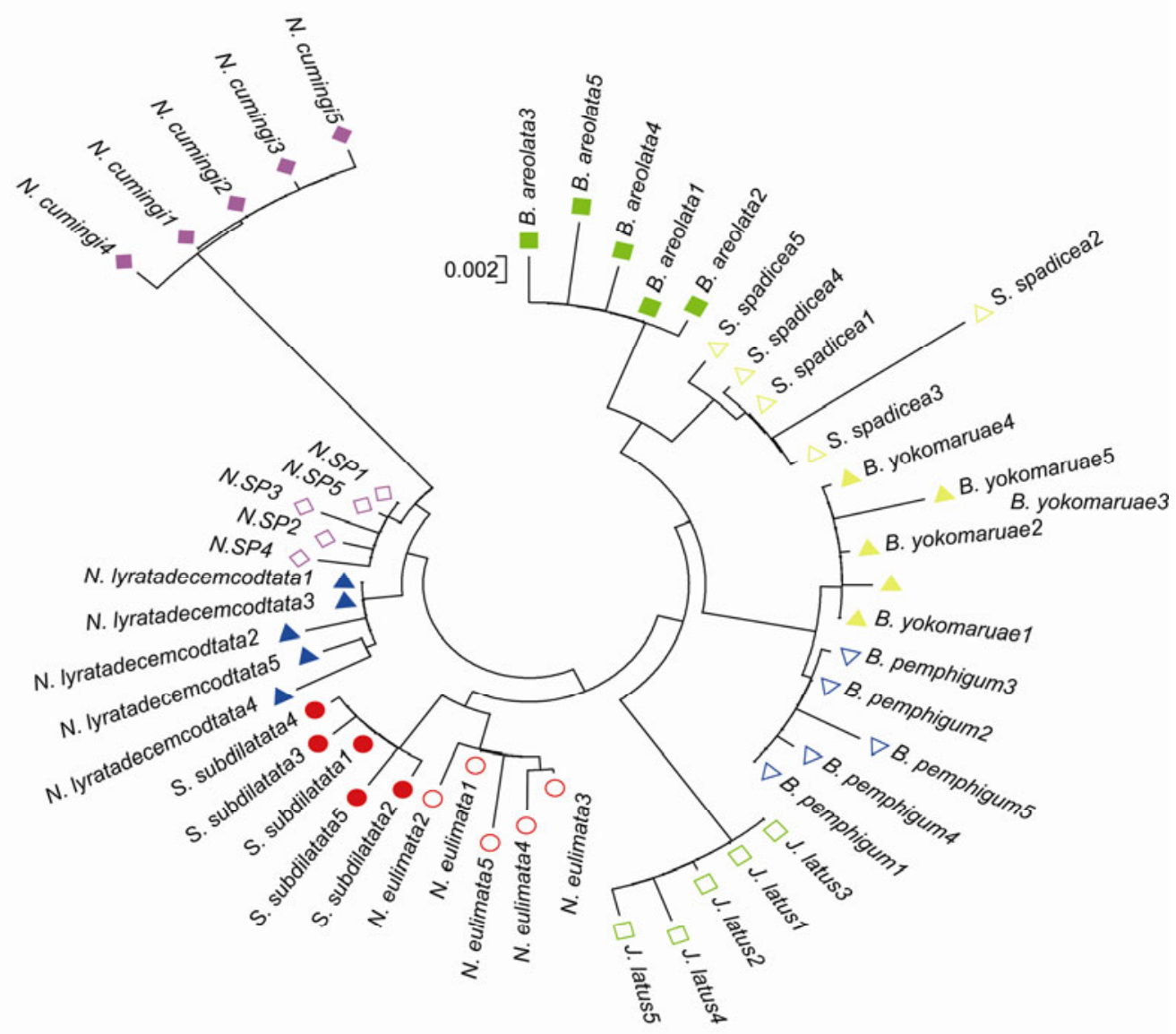

Figure 4 Concatenated neighbor-joining (NJ) tree constructed from alignments of 18S rRNA sequences using the Kimura 2-parameter model for 50 individuals of 10 common Buccinidae species from China. 
evolutionarily saturated. This result was probably caused by a single or multiple transitions, leading to the accumulation of transitions that finally reached an equilibrium [41].

For the phylogeny of 18 Buccinidae whelk species from China, the species in group 1 were distributed along the east coast of the Liaoning Peninsula and north of the Yellow sea. The unnamed species was allocated to the genus Neptunea based on this phylogenetic analysis, as the three phylogenetic trees indicated that this species belonged to the genus Neptunea. The genetic distances between the unnamed species and other species of the genus Neptunea were both at the congeneric level. Consequently, this species should be included in this genus and has been named Neptunea sp. until described as a new species.

It is worth mentioning that SSU clustered with NE (bootstrap value $=85$ ), and was allocated to the genus Neptunea, which conflicts with its contemporary taxonomic status. Although SSU showed a larger distance to SSP than to other species of Neptunea, they both belong to the same genus. This is in accordance with major biological features, such as the shell shape of Neptunea species. Conventional characters also indicate that the genus Neptunea has a close evolutionary relationship to the genus Siphonalia. The noticeable factor that NE and SSP had a very similar shell shape also supported this conclusion.

BP, BY, BST and BS belong to the genus Buccinum. Because of the minimal genetic distances among the species, they are clustered in one clade in all phylogenetic trees. They therefore belong to the monophylum Buccinum.

JL was only distributed in the area near Lüshun where it was an original species, and where it evolved independently in the north of China. The phylogenetic tree, which was derived from 18S rRNA, 28S rRNA, and COI gene sequences showed that the genus Japelion had a closer relationship with the genus Neptunea. Both genera are found in the north of China.

$\mathrm{BA}$ and $\mathrm{BL}$ were distributed along the southern coast of China with a distant relationship to other species in the north of China (Figures 1-3). These results indicate that this geographic distance could explain the resulting phylogeny due to its effect on geographic isolation, genetic drift and phylogeny [42].

Qi et al. [7] and Okutan [43] suggested that Neptunea arthritica cumingii is a subspecies of Neptunea arthritica, whereas Min considered Neptunea cumingi as a unique species [44]. In the present study, a shorter genetic distance and a smaller difference of $18 \mathrm{~S}$ rRNA, 28S rRNA and COI sequences between Neptunea cumingi and Neptunea arthritica cumingii demonstrated that they belong to the same species.

We conclude that the sequences of 18S rRNA, 28S rRNA and COI are appropriate as molecular markers to study relatively recent cladogenetic events among the family Buccinidae. This became evident by studying some aspects of the phylogeny of the Buccinidae. Some controversial issues, such as the paraphyletic phylogeny of the Buccinidae and particularities of their evolutionary history, should be further analyzed in future studies.

We express our gratitude to Dr. HOU ShengTao and Mr. BOONEKAMP Lesley (Melbourne) for their critical reading of the manuscript and their helpful suggestions.

1 Hedrick P W. Conservation genetics: Where are we now? Trends Ecol Evol, 2001, 16: 629-636

2 Golikov A N. Molluscs Buccininae of the world Ocean (in Russian). Fauna of the USSR, Mollusca, 1980, 5: 2465

3 Tiba R, Kosuge S. North Pacific Shells (14) Genus Buccinum Linnaeus. Occasional Publication of the Institute of Malacology of Tokyo, 1984. 124

4 Higo S, Callomon P, Goto Y. Catalogue Bibliography of the Marine Shell-bearing Mollusca of Japan. Osaka-fu, Japan: Elle Scientific Publications, 1999. 749

5 Zhao R Y, Cheng J M, Zhao D D. Mollusca Graphy Around the Dalian Coast (in Chinese). Beijing: Ocean Press, 1982. 60-64

6 Qi Z Y, Ma X T, Lou Z K, et al. Animal Atlas of China (in Chinese). Mollusca, Volume 2. Beijing: Science Press, 1983. 89-96

7 Qi Z Y, Ma X T, Wang Z Y. Mollusca of the Yellow Sea and Bohai Sea (in Chinese). Beijing: Agriculture Press, 1989. 62-67

8 Cai Y Y, Zhang Y, Wei R F. Malacology Conspectus (in Chinese). Shanghai: Shanghai Science and Technology Press, 1995. 229-230

9 Steiner G, Mueller M. What can 18S rDNA do for bivalve phylogeny? J Mol Evol, 1996, 43: 58-70

10 Stroben E, Oehlmann J, Fioroni P. The morphological expression of imposex in Hinia reticulata (Gastropoda: Buccinidae): A potential indicator of tributyltin pollution. Mar Biol, 1992, 113: 625-636

11 Halasewylch M G, McArthur A G. A molecular phylogeny of the Patellogastropoda (Mollusca: Gastropoda). Mar Biol, 2000, 137: 183-194

12 Grande C, Templado J, Cervera J L, et al. Molecular phylogeny of Euthyneura (Mollusca: Gastropoda). Mol Biol Evol, 2004, 21: 303-313

13 Ryan A T. Using 18S rDNA to resolve diaptomid copepod (Copepoda: Calanoida: Diaptomidae) phylogeny: An example with the North American genera. Hydrobiologia, 2004, 519: 135-141

14 Naganuma T, Hisadome K, Shiraish K, et al. Molecular distinction of two resemblant abalones, Haliotis discus and Haliotis discus hannai by $18 \mathrm{~S}$ rDNA sequences. J Mar Biotechnol, 1998, 6: 59-61

15 Winnepenninckx B, Backeljau T, Steiner G, et al. Details of gastropod phylogeny inferred from 18S rRNA sequences. Mol Phylogenet Evol, 1998, 9: 55-63

16 Winnepenninckx B, David G R, Backeljau T. Performance of $18 \mathrm{~S}$ rRNA in littorinid phylogeny (Gastropoda: Caenogastropoda). J Mol Evol, 1998, 47: 586-596

17 Yoon S H, Kim W. Phylogenetic relationships among six Vetigastropod subgroups (Mollusca, Gastropoda) based on 18S rDNA sequences. Mol Cells, 2005, 19: 283-288

18 Iguchi A, Ito H, Ueno M, et al. Molecular phylogeny of the deep-sea Buccinum species (Gastropoda: Buccinidae) around Japan: Inter- and intraspecific relationships inferred from mitochondrial 16SrRNA sequences. Mol Phylogenet Evol, 2007. 44: 1342-1345

19 Hayashi S. The molecular phylogeny of the Buccinidae (Caenogastropoda: Neogastropoda) as inferred from the complete mitochondrial $16 \mathrm{~S}$ rRNA gene sequences of selected representatives. Molluscan Res, 2005, 25: 85-98

20 Kano Y, Chiba S, Kase T. Major adaptive radiation in neritopsine gastropods estimated from 28S rRNA sequences and fossil records. Proc Roy Soc B Biol Sci, 2002, 269: 2457-2465

21 Sun Y, Zhong Y C, Song W Q, et al. Detection of genetic relationships among four Artemia species using randomly amplified polymorphic DNA (RAPD). Intl J Salt Lake Res, 1999, 8: 139-147

22 Hou L, Lü H L, Zou X Y, et al. Genetic characterizations of Mactra 
veneriformis (Bivalve) along the Chinese coast using ISSR-PCR markers. Aquaculture, 2006, 261: 865-871

23 Birnboim H C, Doly J. A rapid alkaline extraction procedure for screening recombinant plasmid DNA. Nucleic Acids Res, 1979, 7: 1513-1522

24 Thompson J D, Gibson T J, Plewniak F, et al. The Clustal X windows interface: Flexible strategies for multiple sequence alignment aided by quality analysis tools. Nucleic Acids Res, 1997, 24: 4876-4882

25 Swofford D L. PAUP*. Phylogenetic Analysis Using Parsimony (* and Other Methods) Version 4. Sinauer Associates, Sunderland, MA, 2001

26 Tamura K, Dudley J, Nei M, et al. MEGA4: Molecular Evolutionary Genetics Analysis (MEGA) software version 4.0. Mol Biol Evol, 2007, 24: 1596-1599

27 Kimura M. A simple method for estimating evolutionary rates of base substitutions through comparative studies of nucleotide sequences. J Mol Evol, 1980, 16: 111-120

28 Woese C R, Fox G E. Phylogenetic structure of the prokaryotic domain: The primary kingdoms. Proc Natl Acad Sci USA, 1977, 74: 5088-5090

29 Cedergen R, Gray M W, Abel Y, et al. The evolutionary relationships among known life forms. J Mol Evol, 1988, 28: 98-112

30 Hasegawa M, Hashimoto T, Adachi J, et al. Early branching in the evolution of eukaryotes: Ancient divergence of Entamoeba that lacks mitochondria revealed by protein sequence data. J Mol Evol, 1993, 36: $380-388$

31 Bi X D, Hou L, Liu X H, et al. The applications of rRNA genes to molecular systematics of marine animals (in Chinese). Chin J Appl Environ Biol, 2005, 11: 779-783

32 Bernardi G, Powers D A. Molecular phylogeny of the prickly shark, Echinorhinus cookei, based on a nuclear (18S rRNA) and a mitochondrial (cytochrome $b$ ) gene. Mol Phylogenet Evol, 1992, 1: 161-167

33 Riutort M, Field K G, Turbeville R, et al. Enzyme electrophoresis, 18S rRNA sequences, and levels of phylogenetic resolution among several species of freshwater planarians (Platyhelminthes, Tricladida,
Paludicola). Can J Zool, 1992, 70: 1425-1439

34 Han H Y, McPheron B A. Phylogenetic study of selected Tephritid flies (Insecta: Diptera: Tephritidae) using partial sequences of the nuclear 18S ribosomal DNA. Biochem Syst Ecol, 1994, 22: 447-457

35 Wright A G, Lynn D H. Phylogeny of the fish parasite Ichtyophthiri$u s$ and its relatives Ophryoglena and Tetrahymena (Ciliophora, Hymenostomatida) inferred from $18 \mathrm{~S}$ ribosomal RNA sequences. Mol Biol Evol, 1995, 12: 285-290

36 Harasewych M G, Adamkewicz S L, Blake J A, et al. Phylogeny and relationships of pleurotomariid gastropods (Mollusca: Gastropoda): An assessment based on partial 18S rDNA and cytochrome $c$ oxidase I sequences. Mol Mar Biol Biotechnol, 1997, 6: 1-20

37 Kaukas A, Rollinson D. Interspecific variation within the "hypervariable" region of the $18 \mathrm{~S}$ ribosomal RNA gene among species of Schistosoma Weinland, 1858 (Digenea). Syst Parasitol, 1997, 36: 157-160

38 Teletchea F, Laudet V, Hanni C. Phylogeny of the Gadidae (sensu Svetovidov, 1948) based on their morphology and two mitochondrial genes. Mol Phylogenet Evol, 2006, 38: 189-199

39 Doiuchi R, Nakabo T. Molecular phylogeny of the stromateoid fishes (Teleostei: Perciformes) inferred from mitochondrial DNA sequences and compared with morphology-based hypotheses. Mol Phylogenet Evol, 2006, 39: 111-123

40 Knight A, Mindell D P. Substitutions bias weighting of DNA sequence evolution and the phylogenetic position of Fea's viper. Syst Biol, 1993, 42: 18-31

41 Desalle R, Freedman T, Prager E M, et al. Tempo and mode of sequence evolution in mitochondrial DNA of Hawaiian Drosophila. J Mol Evol, 1987, 26: 157-164

42 Ward R D, Jorstad K E, Maguire G B. Microsatellite diversity in rainbow trout (Oncorhynchus mykiss) introduced to Western Australia. Aquaculture, 2003, 219: 169-179

43 Okutan T. Marine Mollusks in Japan. Tokyo, Japan: Tokai University Press, 2000

44 Min D K. Mollusks in Korea. Seoul, Korea: Min Molluscan Research Institute Press, 2004

Open Access This article is distributed under the terms of the Creative Commons Attribution License which permits any use, distribution, and reproduction in any medium, provided the original author(s) and source are credited. 